\title{
DESCONTRUINDO DISCURSOS EMANCIPATÓRIOS: UM OLHAR FEMINISTA SOBRE A PERSONAGEM FEMININA NAS ESFERAS DE PODER EM “ENTREVISTA AO VIVO", DE LUCI COLLIN
}

\author{
Lígia Amorim Neves \\ Universidade Estadual de Maringá
}

\begin{abstract}
Resumo: Este artigo objetiva refletir sobre a influência das conquistas do feminismo na construção de identidades da mulher consciente de sua potencialidade transformadora. Para tanto, faz-se uma análise do conto "Entrevista ao vivo" (Inescritos, 2003), de Luci Collin, por se tratar de uma narrativa que põe em discussão a consciência do sujeito feminino da enunciação. Como abordagem teórica para tratar de questões sobre as relações de poder entre os gêneros e a representação literária, empreende-se a perspectiva da Crítica Feminista.
\end{abstract}

Palavras-chave: Representação feminina; Relações de poder; Crítica Feminista

\section{Introdução}

O feminismo, enquanto pensamento crítico e prática política, assume uma responsabilidade historicamente adquirida de contribuir para a democratização em diversas instâncias da vida social. Nesse sentido, esse movimento tem promovido conquistas nas esferas política, econômica, legal, sexual e comportamental.

Diante desse cenário de abertura a possibilidades, e não de amor fati, conforme descreve Bourdieu, "inclinação corporal a realizar uma identidade constituída em essência 


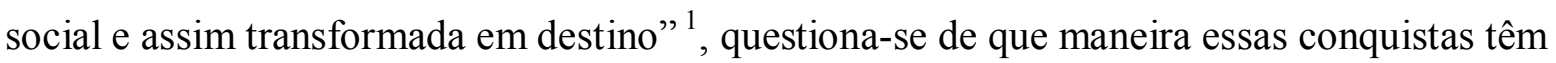
contribuído para a construção de identidades femininas conscientes de sua potencialidade transformadora e de sua ação democrática.

Para refletir sobre esse assunto, faz-se uma análise, a partir da Teoria Crítica Feminista, sobre a personagem feminina no conto "Entrevista ao vivo", do livro Inescritos (2003), de Luci Collin, por se tratar de uma narrativa que põe em discussão a consciência do sujeito feminino da enunciação. Dessa forma, pretende-se explorar a representação de uma das identidades feminina no cenário contemporâneo, a saber, a mulher que desfruta das esferas de poder antes restritas à sociodicéia masculina.

\title{
Desenvolvimento
}

É indiscutível as contribuições que o feminismo tem proporcionado para a reconstrução da "história do trabalho histórico de des-historicização", impedindo, dessa forma, o movimento de eternização das estruturas da divisão de gêneros, enquanto habitus sexuado, e dos princípios de divisão correspondentes ${ }^{2}$.

Ao lutar pelo reconhecimento de uma identidade feminina, descentralizando o conceito do sujeito cartesiano e sociológico, Hall (1997) interpreta o feminismo como um dos "novos movimentos sociais" da chamada "modernidade tardia", que emergiram durante os anos sessenta:

\begin{abstract}
O feminismo [...] questionou a clássica distinção entre o "dentro" e o "fora", o "privado" e o "público". O slogan do feminismo era: "o pessoal é político". Ele abriu, portanto, para a contestação política, arenas inteiramente novas de vida social: a família, a sexualidade, o trabalho doméstico, a divisão doméstica do trabalho, o cuidado com as crianças etc. ${ }^{3}$
\end{abstract}

Essa discussão do modelo patriarcal de construção de sociedade, que destina às mulheres o lugar de coadjuvantes do processo histórico é, certamente, uma das grandes

\footnotetext{
${ }^{1}$ BOURDIEU, Pierre. A dominação masculina. Trad. Maria Helena Kühner. 4.ed. Rio de Janeiro: Bertrand Brasil, 2005, p. 63.

${ }^{2}$ BOURDIEU, Op. Cit., p. 100.

${ }^{3}$ HALL. Stuart. Identidades culturais na pós-modernidade. Trad. Tomaz Tadeu Silva e Guacira Lopes Louro. Rio de janeiro: DP\&A, 1997, p. 49
} 
contribuições da crítica feminista - cuja origem remonta a 1970, com a publicação da tese de doutorado de Kate Milet, Sexual politics ${ }^{4}$.

Isso porque a reconstrução da história da vida privada permite a desconstrução das relações de gênero organizadas sob o signo da opressão e da dependência ou, pelo menos, consegue romper, em determinadas áreas do espaço social, "o círculo do reforço generalizado", impedindo que a dominação masculina se imponha "com a evidência de algo que é indiscutível"5.

Até os primeiros movimentos feministas, essa ética androcêntrica é vista de forma natural, isto é, como inquestionáveis prescrições e proscrições arbitrárias que, inscritas na ordem das coisas, imprimem-se insensivelmente na ordem dos corpos, tanto por mimetismo inconsciente quanto por obediência expressa. Segundo Beauvoir, em seu livro O segundo sexo ${ }^{6}$, que reflete sobre a não coincidência entre a identidade natural ou biológica e a identidade de gênero, "ninguém nasce mulher: torna-se mulher", portanto, ser mulher ou ser homem é um construto social.

Em relação ao gênero feminino, tem-se um trabalho árduo, sutil e estratégico de construção de uma identidade definida apenas pela falta de certas virtudes, constituindo-se, assim, em uma entidade negativa. Esse projeto orienta-se, conforme Bourdieu, para a imposição de "limites, todos eles referentes ao corpo, definido para tal como sagrado", cujo símbolo supremo é a cintura, signo de clausura, entre o puro e o impuro.

Essa concepção identitária pode ser confirmada no seguinte esquema de oposições homólogas proposto pelo mesmo autor ${ }^{8}$, no qual a mulher está associada às propriedades consideradas negativas: alto/baixo, em cima/embaixo, na frente/atrás, direito/esquerdo, reto/curvo, seco/úmido, duro/mole, temperado/insosso, claro/escuro, público/ privado.

Nessa lógica de oposição falocêntrica, a moral da honra masculina resume-se em enfrentar, olhar de frente e com a postura ereta, enquanto que:

a submissão feminina parece encontrar sua tradução natural no fato de se inclinar, abaixar-se, curvar-se, se submeter, (o contrário de 'pôr-se acima de'), nas posturas

\footnotetext{
${ }^{4}$ ZOLIN, Lúcia Osana. O. Desconstruindo a opressão: a imagem feminina em A república dos sonhos de Nélida Piñon. Maringá: Eduem, 2003, p. 11.

${ }^{5}$ BOURDIEU, Op. Cit., p. 106.

${ }^{6}$ BEAUVOIR, Simone de. O segundo sexo II: a experiência vivida. 2 ed. Trad. de Sérgio Milliet. São Paulo:

Difusão Européia do Livro, 1967, p. 09.

${ }^{7}$ BOURDIEU, Op. Cit., p. 25.

${ }^{8}$ BOURDIEU, Op. Cit., p. 16.
} 
curvas, flexíveis, e na docilidade correlativa que se julga convir à mulher [...] como se a feminilidade se medisse pela arte de 'se fazer pequena".

Com base nessa diferença biológica hierarquizada, conclui o autor, o princípio do primado masculino justifica e naturaliza "a diferença socialmente construída entre os gêneros" ${ }^{\prime 10}$, estabelecendo, por conseguinte, a divisão das atividades produtivas a que se associa a ideia de trabalho.

Aos homens, atribui-se "o monopólio de todas as atividades oficiais, públicas, de representação", enquanto que às mulheres, situadas do lado úmido, baixo e curvo, destinam-se “os trabalhos domésticos, ou seja, privados e escondidos, ou até mesmo invisíveis e vergonhosos", os quais, por não ter valor de mercado, são desvalorizados, inclusive pelas próprias mulheres ${ }^{11}$.

O principal fator de mudança nessa sociodicéia masculina tem sido a educação. Segundo descreve Bourdieu ${ }^{12}$, a partir do momento em que se tem o acesso ao ensino secundário e superior, torna-se possível dar início a um processo rumo à conquista da independência econômica da mulher (trabalho assalariado, acesso à esfera pública) e a transformações das estruturas familiares (distanciamento das tarefas domésticas; adiamento da idade do casamento e da procriação - relacionado com o progresso e o uso generalizado de técnicas anticonceptivas; redução de tamanho das famílias; elevação dos percentuais de divórcios; queda dos percentuais de casamento).

A partir dessa ruptura com aquela identidade feminina privada do acesso à esfera pública e à própria privacidade da vida privada - lugar da privação, e não o espaço da privacidade -, instaura-se, segundo a socióloga Ávila, um horizonte de possibilidades para as mulheres "se transformarem em cidadãs, o que significa ter existência própria dotada de autonomia e direitos"13.

Com efeito, realizam-se transformações nas estruturas produtivas, o que leva a mudanças das posições ocupadas pelas mulheres no trabalho. No entanto, a lógica do modelo tradicional entre os gêneros ainda é predominante na sociedade. Isso porque, explica

\footnotetext{
${ }^{9}$ BOURDIEU, Op. Cit., p. 38-39.

${ }^{10}$ BOURDIEU, Op. Cit., p. 20.

${ }^{11}$ BOURDIEU, Op. Cit., p. 41 e 60.

${ }^{12}$ BOURDIEU, Op. Cit., p. 107.

13 ÁVILA, Maria Betânia. Feminismo e sujeito político. Revista Proposta, Rio de Janeiro, n. 84-85, p. 7-11, mar./ ago. 2000, p. 7.
} 
Bourdieu, "os homens continuam a dominar o espaço público e a área de poder" ${ }^{\prime 4}$, ao passo que as mulheres, a esfera do privado (doméstico, lugar de reprodução) ou suas extensões:

\begin{abstract}
Observa-se, assim, um forte aumento da representação de mulheres nas profissões intelectuais ou na administração e nas diferentes formas de venda de serviços simbólicos (jornalismo, televisão, cinema, rádio, relações públicas, publicidade, decoração) e também uma intensificação de sua participação nas profissões mais próximas da definição tradicional de atividades femininas (ensino, assistência social, atividades paramédicas). Apesar disso, as diplomadas encontraram sua principal oferta de trabalho nas profissões intermediárias de nível médio (quadro administrativos de nível médio, técnicos, membros do corpo médico e social etc.), mas continuam vendo-se praticamente excluídas dos cargos de autoridade e de responsabilidade, sobretudo na economia, nas finanças e na política ${ }^{15}$.
\end{abstract}

Verifica-se, portanto, que o direito de inserção da mulher na vida pública não significa uma transformação das relações de gênero, uma vez que o processo de libertação dos esquemas do inconsciente engendrados em uma relação de dominação é lento. No concernente a isso, reflete Bourdieu, não se pode "esperar a liberação das mulheres como efeito automático de sua "tomada de consciência"", ", ignorando os efeitos duradouros que a violência simbólica impõe aos dominados.

Por isso o autor defende que "só se pode chegar a uma ruptura de cumplicidade que as vítimas da dominação simbólica têm com os dominantes com uma transformação radical das condições sociais de produção"17. Desse modo, pode-se impedir que os dominados reproduzam a ideologia androcêntrica, orientando-se, assim, para um projeto coletivo de horizontalidade.

É nesse contexto em que se encontra a narrativa a ser analisada. Diante de uma personagem feminina que usufrui conquistas do feminismo nas esferas política, legal e econômica, mas que não tem consciência de sua potencialidade transformadora, o conto permite refletir o significado desse complexo projeto feminista de emancipação da mulher no cenário contemporâneo. No texto, a personagem Mara é introduzida como a vencedora do título, cujo motivo dessa premiação, na perspectiva da protagonista, deve-se a sua postura crítica alicerçada em uma consciência preocupada com as questões político-sociais. Todavia, no decorrer da leitura, as perspectivas põem em movimento um jogo específico de correlações que levam a outro horizonte de sentido, como será visto no decorrer dessa análise.

\footnotetext{
${ }^{14}$ BOURDIEU, Op. Cit., p. 112.

${ }^{15}$ BOURDIEU, Op. Cit., p. 109.

${ }^{16}$ BOURDIEU, Op. Cit., p. 53.

${ }^{17}$ BOURDIEU, Op. Cit., p. 54.
} 
Nesse sentido, Luci Collin ${ }^{18}$ permite um olhar feminista sobre "Entrevista ao vivo", que integra a coletânea de contos Inescritos (2004). Sobre o livro, escreve Nelson de Oliveira, escritor e mestre em Letras pela USP:

São vinte narrativas submetidas a vinte diferentes formas, incluindo a paródia desvirtuada e fragmentada do ensaio acadêmico, da entrevista, do roteiro cinematográfico, do comercial de televisão, da homenagem póstuma e do diário de adolescente. Várias dessas narrativas realmente contam uma história, outras não narram nada, não têm enredo, realizando-se na cristalização lírica, na justaposição de sons, cores e cheiros ${ }^{19}$.

O texto, cuja ação resume-se em uma entrevista concedida pela protagonista, Mara, por ter sido eleita a brasileira do século, apresenta-se inteiramente sob a forma desse gênero textual, por meio do diálogo, o qual trabalha com a estrutura de vazios, já que "a réplica tenta ocupar o que permaneceu vazio na enunciação do outro" ${ }^{20}$. A cada enunciação motivada pela pergunta, ou seja, pelas condições específicas, surge um novo lugar vazio, afinal as respostas também contêm motivos ocultos. Dessa forma, cresce a imprevisibilidade do dito e as representações que os personagens criam a respeito de si.

Nesse gênero de tom especulativo, tem-se a oportunidade de recolher dados não disponíveis em fontes documentais, e informações autênticas, haja vista o fato de ser uma entrevista ao vivo, o que implica ausência de qualquer trabalho de edição sobre a linguagem. Ou seja, não se trata de discursos simulados ou transformados, fato este que concede ao leitor o acesso direto às informações compartilhadas entre os únicos personagens desse conto: a entrevistada, Mara, e o entrevistador, Célio.

\footnotetext{
${ }^{18}$ Luci Collin (Curitiba, 1964) graduou-se em Letras Português/Inglês, no Curso Superior de Piano e no de Percussão Clássica. É Mestre em Letras pela UFPR (com a dissertação "The Quest Motif in Snyder's The Back Country"), doutoranda na USP (com a tese "A composição multidiscursiva: o pictórico e o cinemático nos retratos literários de Gertrude Stein") e professora de Literaturas de Língua Inglesa na UFPR. Já lecionou música e atuou como instrumentista (1985-93), trabalhou como tradutora (1987-96), presidiu a Cooperativa de Artes do Paraná (1984-85), representou o Brasil no Projeto Literário da EXPO 2000 em Hanover, Alemanha, e recebeu premiações em concursos de literatura no Brasil e nos EUA. Além de ter participado de antologias no Brasil e no exterior, já teve cinco textos dramáticos encenados e diversos livros publicados, a saber: os de poesia Estarrecer (1984), Espelhar (1991), Esvazio (1991), Ondas e Azuis (1992), Poesia Reunida (1996), Todo Implícito (1998); e os de contos Lição Invisível (1997), Precioso Impreciso (2001) e Inescritos (2004) e Vozes num divertimento (2008).

19 OLIVEIRA, Nelson de. Inescritos, de Luci Collin. Jornal de Poesia. Disponível em: $<$ http://www.revista.agulha.nom.br/nelsonoliveira9.html> Acesso em: 15 de ago. 2009.

${ }^{20}$ ISER, Wolfgang. O ato da leitura: uma teoria do efeito estético. vol. 2. Tradução Johannes Kretschmer. São Paulo: Ed. 34, 1999, p. 142.
} 
É na confluência entre essas duas perspectivas e a do autor implícito que se constroem as identidades das personagens. Ainda que se tenham poucos elementos caracterizando o entrevistador, o percurso investigativo do questionário que ele direciona a Mara, o qual é condicionado também por suas respostas, aponta para um personagem irônico e crítico, preocupado em desvelar a identidade da entrevistada, como mostram os exemplos adiante.

Logo na primeira pergunta, Célio comete um erro no nome dela: Célio Ventura: Nara, quero primeiro agradecer sua gentileza de ter... / Mara Stefan: ... é Mara, com 'm', Célio..." / C: Me desculpe... pois é, Mara, enfim, [...]"21. Em um primeiro momento, esse lapso pode sugerir uma desatenção dele, no entanto, tendo em vista o tom irônico no decorrer da entrevista, outras ideias serão suscitadas e confirmadas, preenchendo um horizonte que, no momento, ainda se encontra vazio.

Ao fim da narrativa, o leitor é autorizado a ressignificar esse erro cometido por Célio em relação à identidade da entrevistada, entendendo-o como um indício de desprezo dele, e até de deboche, por aquela "celebridade", como se a frivolidade dela já fosse conhecida pelo entrevistador, tal qual se observará pelo modo tendencioso de suas perguntas, orientadas para revelar atributos que constroem uma imagem negativa dessa mulher.

Tal episódio também se apresenta como um sinal para o leitor ficar atento às intenções do entrevistador e, assim, desconfiar de suas perguntas aparentemente simples e/ou ingênuas. Afinal, o discurso lacunar de Célio é um mecanismo que tenciona a ação, pois, ao formular perguntas sem muitas especificações, o narrador permite à entrevistada particularizar o assunto em questão da forma que lhe convier, configurando, assim, uma estratégia do entrevistador para revelar a formação ideológica a que Mara se filia, como se vê nas respostas às seguintes perguntas: "E as drogas?" e "Para finalizar, Mara, projetos?", em que a entrevistada assume um ponto de vista egocêntrico, como será visto adiante.

Ao olhar para a primeira pergunta da entrevista, o leitor consegue apreender o motivo da entrevista e da escolha da entrevistada, a saber, alguém que recebeu um título importante: “C: Me desculpe... pois é, Mara, enfim, como é que você está se sentindo agora que foi escolhia 'A brasileira do século' pela revista 'Sistema Et Criatividade'?"22. Contudo, ao realizar uma leitura mais cautelosa, desmorona-se o caráter meramente referencial desse

\footnotetext{
${ }^{21}$ COLLIN, Luci. Inescritos. Curitiba: Travessa dos Editores, 2004, p. 91.

${ }^{22}$ COLLIN, Op. Cit., p. 91
} 
enunciado, o de informar o motivo da entrevista, pois o título de "brasileira do século", sendo de uma magnitude extravagante, requer desconfiança por parte do leitor, afinal, não se trata de um ano, uma década ou meio século - o que já seria notável.

Nisso se mostra uma peculiaridade do uso icônico dos signos, segundo Iser, que é a de não ser mera comunicação de objetos, pois se trata "de imaginar o que os signos, em face do que denotam, passaram a excluir." ${ }^{23}$ É daí que surge o objeto imaginário, antes mera virtualidade $^{24}$. Em face desses signos, "brasileira do século", revela-se aqui, logo na primeira pergunta, o ponto de vista do autor implícito do texto, que está marcado pela ironia: se, na visão de Mara, a pergunta cumpre apenas uma função referencial, na do autor implícito, os signos já carregam um tom de jocosidade, por se tratar de um título esdrúxulo.

Diante da resposta confusa e inconsistente de Mara a essa pergunta, somada às outras ao longo da narrativa, como serão analisadas, confirma-se aquela suspeita de identidade superficial estimulada pelo texto. Ou seja, o horizonte aberto que estava vazio, na expectativa do que viria, é preenchido e satisfeito, e o horizonte anteriormente estabelecido e satisfeito se esvazia, configurando a dialética de protensão e retenção descrita por Iser $^{25}$. Isso porque a entrevistada não revela, durante a entrevista, algum projeto alicerçado em uma consciência de transformação social que justifique a conquista daquele prêmio ilustre:

C: Me desculpe... pois é, Mara, enfim, como é que você está se sentindo agora que foi escolhia "A brasileira do século" pela revista "Sistema Et Criatividade"?

M: Olha, Nélio, bom... sei lá, não posso dizer que, bom... feliz porque venho lutando por isso há mais de vinte e cinco anos, quer dizer, não são vinte e cinco dias, entende? Eu vejo isso como uma vitória da mulher, indiscriminada, no sentido que nós estamos virando a mesa, tendo iniciativa privada, efetivando, sabe como $?^{26}$

Em vista desses fatos, o leitor também é autorizado a desconfiar da natureza da entidade responsável por essa premiação, a saber, a revista "Sistema Et Criatividade", nome, aliás, que não inspira um veículo comprometido com questões político-sociais. Diante dessa articulação, a hesitação de Mara em sua resposta, fato este que poderia denotar um tom de cansaço devido a tantos anos de luta da mulher por direitos iguais, abre espaço para outras formações de sentido, haja vista que não existem evidências de engajamento dela com

\footnotetext{
${ }^{23}$ ISER, Wolfgang. $O$ ato da leitura: uma teoria do efeito estético. vol. 1. Tradução Johannes Kretschmer. São Paulo: Ed. 34, 1996, p. 122.

${ }^{24}$ ISER, Op. Cit., p. 123.

${ }^{25}$ ISER, Op. Cit., p. 17.

${ }^{26}$ COLLIN, Op. Cit., p. 91.
} 
questões externas às suas próprias preocupações, como as suas respostas mostram ao longo da entrevista.

Como a combinação mais óbvia não se comprova, resta ao leitor, diante da possibilidade problematizada, procurar outra Gestalt capaz de representar a relação de signos, isto é, outra percepção dos acontecimentos da narrativa, a saber: é por sua promoção pessoal, de fato, que Mara vem lutando "há mais de vinte e cinco anos", afinal, como ela diz, "não é da noite pro dia que a gente se torna popular, se torna "alguém",27.

Em face dessas duas grandes constatações, a de que o mérito do título de "brasileira do século" não está vinculado a um projeto democrático e libertador de comprometimento com a sociedade, e a de que a eleita filia-se a uma formação ideológica excêntrica, cujo sentido se encontra em "ser popular", estabelece-se outro horizonte de potências de significados. Nessa visão projetada, as práticas descritas pela personagem são lidas como estratégias oportunistas.

Uma dessas práticas é a exploração de sua imagem na mídia. Quando indagada se "as fotos pra aquela revista masculina, ajudaram?"28, além da afirmação implícita do entrevistador referente à pergunta, tem-se uma alusão ao tipo de fotos, como sendo de exposição do corpo, o que configura uma estratégia de promoção pessoal. Mas tal suposição deve-se não somente ao fato de ser uma revista masculina, afinal, essa categoria de suporte também comporta assuntos e imagens de natureza diferente dessa referente à exposição corporal.

A justificativa responsável por permitir que o leitor aceite essa alusão é o jogo argumentativo confuso e fútil da protagonista. Por se tratar de um discurso desprovido de uma postura ideológica realmente engajada com um projeto de transformação social, o leitor é autorizado a substituir aquela representação de mulher produzida pelas posições textuais dadas por outra capaz de corresponder às novas perspectivas matizadas no texto por meio dos vazios. Assim, segundo Iser, o leitor é impulsionado "a direcionar a representação para a significância não-verbalizada pelo texto"29, a de que a exposição corporal de Mara, em detrimento de seu modo de pensar, tenha sido um meio mais eficiente para ela atingir a notoriedade popular.

\footnotetext{
${ }^{27}$ COLLIN, Op. Cit., p. 91-92.

${ }^{28}$ COLLIN, Op. Cit., p. 92.

${ }^{29}$ ISER, Op. Cit, p. 71.
} 
Convém ressaltar que a exposição corporal da mulher não constitui o problema aqui, afinal, a mulher tem sido vítima de uma nova submissão: a de cobrir o seu corpo, pela conotação historicamente negativa que ele carrega. Aceitar esse comportamento é aderir à doxa masculina e tradicionalista, a qual tenta provar que toda mulher que expõe a sua beleza física não tem valor enquanto ser intelectual e político, por exemplo.

Uma segunda prática oportunista diluída em seu discurso é o fato de Mara permanecer com o sobrenome do segundo marido que, pelo modo como ela se refere a ele, não parece ser o atual companheiro: “C: Daí o Stefan? M: Não, este é o sobrenome do meu segundo marido, que eu adotei”, ${ }^{30}$. Essa atitude aponta para um interesse particular, conforme o encadeamento de elementos ao longo da narrativa, afinal, Mara poderia trocar de sobrenome, como já o fez ao adotar "Stefan". Contudo, ela o mantém, e isso possivelmente se deve menos à dificuldade em realizar essa mudança, tal como ela tenta convencer o seu interlocutor - "E eu detesto toda a burocracia que existe pra mudar de nome, sabe como?",31-, que ao fato de se tratar de um sobrenome tipicamente alemão, o que lhe confere um status positivamente diferenciado na esfera social.

Um último fator importante para a sua ascensão popular diz respeito ao seu envolvimento com poderosos, informação que lhe escapa em meio ao seu discurso:

"Eu conquistei isto hoje" é fruto do teu verdadeiro esforço quando você se fez
necessário. Eu venho fazendo parte da história deste país, voto, sou votada,
participo, tive grandes amores entre os "poderosos"... (risos) e mesmo assim você
chega na minha casa na hora que quiser que eu sou a mesma de vinte anos atrás.
Nunca saí por aí espalhando segredos (risos) e tento não magoar as pessoas que me
rodeiam ${ }^{32}$.

Diante dessa confissão, o leitor é autorizado a pensar que as conquistas na esfera pública das posições de senadora, primeira-dama, professora emérita nos Estados Unidos e escritora devem-se menos a fatores associados à competência intelectual, que a situações oportunistas, como relacionamentos com pessoas influentes.

Tendo em vista todas essas evidências, compreende-se, por extensão das relações estabelecidas no texto, o modo pelo qual Mara conquistou 190.000 votos, em Suri. E isso pode ser definitivamente significativo em se tratando de uma "cidadezinha", "um lugarzinho

\footnotetext{
${ }^{30}$ COLLIN, Op. Cit., p. 93.

${ }^{31}$ COLLIN, Op. Cit., p. 93.

${ }^{32}$ COLLIN, Op. Cit., p. 95.
} 
perdido no mapa"33, como ela mesma se refere a sua cidade natal. Assim define-se a sua trajetória de "luta", evidenciando, portanto, uma vida conquistada e promovida à base de mecanismos oportunistas.

Mara, não obstante, tenta sustentar uma postura ideológica arraigada em um projeto democrático de emancipação. No entanto, o conjunto de temas e de figuras que materializam a sua visão de mundo, não condiz com a formação ideológica a que ela pensa estar filiada, como revelam os seguintes excertos:

\begin{abstract}
C: Daí o Stefan?
M: Não, este é o sobrenome do meu segundo marido, que eu adotei. E eu detesto toda a

burocracia que existe pra mudar de nome, sabe como? Sou, sou reacionária, Célio! Você tem direitos e as pessoas te alienam e simplesmente se fazem de cegas! Eu acho isto in-crííiiivel! [...] $]^{34}$.

$\mathrm{C}: \mathrm{E}$ as drogas?

$\mathrm{M}$ : Eu vejo sob um outro prisma. Tento relaxar. Bom, eu nunca usei. Quer dizer, coisa pesada, sabe? Antigamente a gente queria paz e queria certeza. Hoje você vai ao supermercado e cada dia é uma coisa em oferta e a gente consome mesmo sabendo que o preço tá embutido! Percebe a diferença? A diferença, não! As diferenças, porque são muitas. E eu sou meio contracultura, quer saber? A Fátima, minha copeira, me disse: "Mas por que tanto livro, dona Mara?!" E eu respondi: "Me chame de Mara!" Eu sou assim, sabe Célio? [...] $]^{35}$.
\end{abstract}

É nesse ponto que se dá um grande choque de perspectivas, pois a representação dos ideais de Mara na sua visão difere daquela imagem matizada pelos vazios do texto. As noções de "ser contracultura" e de "ser reacionária" nesses trechos não estão associadas ao que, de fato, elas significam, pois aderir a um discurso transformador implica assumir uma postura de subversão a esta ordem que está sendo questionada, o que não condiz com as atitudes de Mara, pois ela permanece inserida de forma passiva nessa dinâmica denunciada por ela.

Isso se evidencia na própria concretização do prêmio, "a brasileira do século", metáfora do sucesso de sua luta por uma causa pessoal. Em meio ao seu discurso a respeito do efeito sobre si dessa grande premiação, a protagonista, ressaltando o aspecto temporal para enfatizar o seu trabalho árduo ao longo dos anos, tenta convencer o seu interlocutor de que se trata de uma luta feminina:

C: [...] como é que você está se sentindo agora que foi escolhia "A brasileira do século" pela revista "Sistema Et Criatividade"?

\footnotetext{
${ }^{33}$ COLLIN, Op. Cit., p. 92.

${ }^{34}$ COLLIN, Op. Cit., p. 93.

${ }^{35}$ COLLIN, Op. Cit., p. 94.
} 
M: Olha, Nélio, bom... sei lá, não posso dizer que, bom... feliz, porque venho lutando por isso há mais de vinte e cinco anos, quer dizer, não são vinte e cinco dias, entende? Eu vejo isso como uma vitória da mulher, indiscriminada, no sentido que nós estamos virando a mesa, tendo iniciativa privada, efetivando, sabe como? ${ }^{36}$

Configura-se, aqui, a estrutura da negação, pois "o texto formulado diz o contrário do que formula. $\mathrm{Na}$ melhor das hipóteses, o texto formulado significa algo que não foi formulado",37. Ou seja, a negação marca um defeito no conhecimento familiar, questionando, assim, segundo Iser, a sua validade e expondo aquilo que antes estava encoberto, “consequentemente são problematizadas as normas selecionadas do repertório, assim como os protagonistas e suas ações",38.

Esse discurso feminista emancipatório, não obstante, é negado na estrutura profunda de seu enunciado, pois o que emerge é uma postura ideológica excêntrica e que prima pela aparência. Não se trata de "uma vitória da mulher", mas de um triunfo pessoal da protagonista, cujo objetivo é ser popular e ter prestígio.

E o entrevistador, percebendo essa postura política de Mara, questiona de forma irônica: "C: Mara, podemos então dizer que você é um ser político?" "39. Trata-se de uma pergunta retórica, em que o entrevistador, ao captar o senso político da entrevistada na resposta anterior, o retoma em forma de pergunta, em uma tentativa, possivelmente, de desencadear um discurso que acentua ainda mais essa sua política excêntrica e fútil, que reconhece no título de "brasileira do século" o sentido de sua longa e exaustiva luta.

Esse aspecto egocêntrico é reafirmado na resposta à questão seguinte, que trata sobre o seu envolvimento prático com a política enquanto senadora e primeira-dama. Mara tenta sustentar, na materialidade linguística do texto, uma essência engendrada em esquemas de percepção e de ação políticas de cunho democrático: "Sou. Acho que verdadeiramente cada pedaço de mim mesma tem sempre um compromisso com o outro. Sou política de raiz." ${ }^{40}$

Porém, as suas práticas sociais revelam um jogo de interesses particulares, como já visto, o que autoriza o leitor a desconfiar também das intenções destas práticas: "Eu sempre

\footnotetext{
${ }^{36}$ COLLIN, Op. Cit., p. 91.

${ }^{37}$ ISER, Op. Cit., p. 47.

${ }^{38}$ ISER, Op. Cit., p. 193.

${ }^{39}$ COLLIN, Op. Cit., p. 91.

${ }^{40}$ COLLIN, Op. Cit., p. 91.
} 
me relacionei bem com o pessoal da esquerda, sempre participei avidamente das atividades coletivas do clero, gosto de esporte tipo vôlei, fiz 190.00 votos só em Suri" ${ }^{41}$.

Outra característica em seus discursos é a ideologia elitista. Embora Mara afirme que "o ouro está nas coisas simples que a gente vê" 42 , as suas práticas sociais destoam dessa noção. Por exemplo: ela empenha-se em "ser alguém", o que para ela significa "ser popular"; faz questão de permanecer com um sobrenome alemão; e ostenta um elevado poder aquisitivo que, aliás, em seu caso, a distancia de um senso crítico sobre a esfera econômica.

Essa última constatação pode ser observada em um de seus exemplos frívolos, a saber, quando ela faz referência a sua nova casa na praia feita em mármore. Em face desse fetichismo, questiona-se a sua alienação perante os mecanismos criados pela realidade capitalista para gerar necessidades supérfluas, vazias, individualistas, transformando produtos em relações sociais: uma casa dessa magnitude vale um modo de viver dotado de um status prestigiado.

A importância conferida às aparências também se evidencia na resposta à pergunta que ressalta a aparência como mecanismo de projeção social - "E as fotos pra aquela revista masculina, ajudaram?"43 -, apesar de Mara tentar desenvolver um argumento oposto à afirmação implícita de Célio, a saber, a de que as fotos contribuíram para a sua ascensão social:

\footnotetext{
Eu sempre analiso a pessoa como um ser que vive, é de pele e osso. Agora, perceba que eu não disse "carne e osso", disse "pele" porque eu sou muito desta coisa de pele, de expor o que você tem dentro de você. E também não disse "carne" porque eu não gosto desta palavra. É confusa. Eu inclusive fui vegetariana por mais de quatro semestres, quer dizer, é quase uma vida, né? ${ }^{44}$
}

Ao tentar, sem sucesso, afirmar a importância que ela dispensa à essência do ser, Mara desliza na articulação, progressão e pertinência de suas ideias, ainda mais ao encerrar a sua resposta de forma hiperbólica, afinal, a dimensão temporal da expressão "quatro semestres" - que gera uma ilusão de tempo mais longo que "dois anos" - está muito longe de representar "quase uma vida", tal como ela diz.

\footnotetext{
${ }^{41}$ COLLIN, Op. Cit., p. 92.

${ }^{42}$ COLLIN, Op. Cit., p. 95.

${ }^{43}$ COLLIN, Op. Cit., p. 92.

${ }^{44}$ COLLIN, Op. Cit., p. 92.
} 
Sobre as contradições em seu discurso, que se dá pelas negações, isto é, pelo que o tema exclui, a narrativa, por outro lado, também apresenta ao leitor, de forma explícita, uma evidência de que isso já fora observado por outra pessoa:

C: O Waldiney Lima disse que você foi contraditória no seu último livro. Isto lhe pertuba?

M: Célio, se você nasce numa família como a minha, sabe o que é compra um cacho de uvas e nunca poder... porque o teu bairro não tem tradição de comer uva... e depois passa anos pensando, pensando, até declarar o que estava pensando, então você vai ser considerada contraditória. Não, não fiquei chateada com o Waldi, porque ele sabe que eu gosto dele como um irmão, desde os tempos de "Marcha", e não vai ser uma reflexãozinha supérflua que vai abalar a minha vontade de ser praticamente transparente. ${ }^{45}$

Em outros momentos, a tentativa de afirmar uma postura ideológica de que ela acredita fazer parte resulta em enunciados incoerentes, desconexos, com uma progressão de ideias equivocadas, caracterizando, assim, uma retórica vazia, frágil, tautológica e ineficiente, e um sujeito frágil e manipulável:

Olha, meu amigo, eu tenho duas décadas de United States e aqui a gente tá cercado do chamado "paternalismo compulsório" que amputa o lado mais bonito, o ladinho mais delicado do "aceitar-se" ou "dar-se por vencido". É toda uma dinâmica de dividendo e lucro. Percebe? Por trás dos panos é mais o menos um "know-how" às avessas. $^{46}$

Diante dessas amostras do discurso de Mara, percebe-se, em termos de predominância, um discurso parafrástico. Isso porque ela retorna aos mesmos espaços de dizeres, sem romper com processos de significação: se, na visão da protagonista, são formuladas relações de preocupação com a igualdade, a autonomia, a liberdade, a emancipação e a democracia; o que ressoa da relação entre todas as outras perspectivas do texto são esquemas do inconsciente engendrados em relações de direita, elitista, capitalista, antidemocrática e excêntrica. Assim sendo, a protagonista define-se como um sujeito imerso em uma ideologia da qual acredita estar fora, e não conscientemente dentro e fora dela, como se caracteriza o sujeito que emerge dos escritos e debates do feminismo ${ }^{47}$.

Sobre esse sujeito na esfera da crítica feminista, têm-se as seguintes revisões de conceitos: “inicialmente, falava-se no estudo da categoria 'mulher'; depois, passou-se a

\footnotetext{
${ }^{45}$ COLLIN, Op. Cit., p. 94-95.

${ }^{46}$ COLLIN, Op. Cit., p. 93-94.

47 LAURETIS, Teresa de. A tecnologia do gênero. In: HOLLANDA, Heloísa Buarque de. Tendências e impasses: o feminismo como crítica da cultura. Rio de Janeiro: Rocco, 1994, p. 217.
} 
estudar a categoria de gênero; ultimamente, têm-se buscado substituir o uso de categorias cuja tendência é universalizar a oposição homem/mulher" "48. É o que Lauretis chama de "sujeito do feminismo", uma categoria de análise da figura feminina em sua subjetividade múltipla e não unificada, em detrimento da "Mulher com letra maiúscula", como "representação de uma essência inerente a todas as mulheres" ${ }^{\text {"49. }}$.

Ao descentralizar essa abordagem da mulher, a relação de gênero não é mais tomada como "o dado determinante dos dramas narrados", marcando, assim, uma produção literária cuja construção da identidade feminina figura-se "mais livre do peso das relações de gênero", tal como ocorre no conto em análise $\mathrm{e}^{50}$. O sujeito que emerge do conto aponta para esse conceito de gênero não restrito à diferença sexual, mas a um sujeito gendrado na relação social, de acordo com a definição de gênero de Lauretis: representação não de um indivíduo, mas de uma relação social, "a relação de pertencer a uma classe, um grupo, uma categoria." 51

Por isso o conto permite uma abordagem feminista do momento denominado fase fêmea, pois a tônica não reside sob a afirmação do feminismo enquanto um movimento social e político de luta pelos direitos da mulher, isto é, não se trata de um questionamento da igualdade acima das diferenças de gênero. Também não se refere a uma "fase feminista", de afirmação do universo cultural feminino, momento em que a produção feminista passa a desafiar as narrativas masculinas universalizantes, levando à esfera pública e politizando as histórias da vida privada, do corpo, da sexualidade, da feitiçaria, da prostituição, da família, do trabalho informal, do cotidiano das fábricas e das fazendas ${ }^{52}$.

Trata-se de um momento a que Showalter (1985) denomina "fase fêma", por debruçar-se sobre as diferenças entre as mulheres (e entre os homens também), rumo à autodescoberta, à busca da identidade. ${ }^{53}$ Assim se caracteriza a protagonista: embora a sua trajetória compreenda conquistas feministas nas esferas política, legal, econômica, social, sexual e intelectual, a tônica reside no modo como a personagem constrói a sua identidade frente a esse horizonte de possibilidades.

\footnotetext{
${ }^{48}$ ZOLIN, Op. Cit., p. 73-74

${ }^{49}$ LAURETIS, Op. Cit., p. 217.

${ }^{50}$ ZOLIN, Op. Cit., p. 85.

${ }^{51}$ LAURETIS, Op. Cit., p. 210-211.

52 RAGO, Margareth. Adeus ao feminismo? Feminismo e (pós)modernidade no Brasil.

Cadernos AEL - Arquivo Edgard Leuenroth: mulher, história e feminismo, Campinas, SP, n. 3/4, p. 11-43, 1995/1996, p. 42-43.

${ }^{53}$ SHOWALTER, 1985 Apud ZOLIN, Op. Cit, p. 83.
} 
Diante de uma mulher ex-senadora, primeira-ministra, escritora, professora emérita nos Estados Unidos, que já posou para revista masculina, divorciou-se, trocou de nome, teve um filho e vive sob um teto de mármore, a tensão reside na maneira pela qual a personagem usufrui essas conquistas para a construção de uma identidade feminina consciente de sua potencialidade transformadora. É nesse sentido que se pode pensar a narrativa.

Trata-se de uma representação arquetípica de uma essência feminina erigida para valorizar aspectos supérfluos e exteriores, como a popularidade, a aparência física, o gosto pelo luxo e pelas frivolidades. No entanto, a crítica não se sustenta por esse consumismo e futilidade, tal como criticaram as feministas liberais, por acreditar que essas características não podiam ser conciliadas com assuntos mais sérios. A crítica se justifica pela postura acrítica da protagonista, o que caracteriza uma alienação perante o seu potencial transformador na sociedade.

O fato de uma parcela das mulheres terem alcançado a esfera pública, sobretudo, terem ascendido à política não resulta, portanto, diretamente em uma transformação nas práticas sociais. Não basta o reconhecimento e o acesso a esses direitos, é preciso saber exercer esse poder sem reproduzir discursos contrários a essa concepção democrática e emancipadora responsável por essas conquistas.

Isso é o que ocorre com a protagonista, cuja identidade contraditória se revela por meio da desconstrução de seus discursos, tal como Lauretis explica. A construção do gênero, conforme a autora, "também se faz por meio de sua desconstrução, quer dizer, em qualquer discurso, feminista ou não, que veja o gênero como apenas uma representação ideológica falsa" ${ }^{, 54}$, que contém algo em excesso ou em falta, rompendo ou desestabilizando qualquer representação.

Diante dessa desconstrução por que passa a protagonista, instaura-se a ironia na narrativa, entendida não apenas como figura estilística, mas como um tipo discursivo, conforme Orlandi (2001) amplia essa noção. A ironia contempla a literariedade dos discursos instituídos, ao mesmo tempo em que desloca essa literariedade para a instauração de outros estados de mundo, produzindo, assim, um desvio de sentido - mas não um jogo de oposições. Como define Iser, a ironia serve de trampolim para o que lhe escapa ${ }^{55}$.

\footnotetext{
${ }^{54}$ LAURETIS, Op. Cit., p. 209.

${ }^{55}$ ISER, Op. Cit., p. 47.
} 
Como isso não se manifesta verbalmente na materialidade lingüística da narrativa, ela depende imperiosamente do papel do leitor ativo que é incentivado a construir o "não-dito de cenas aparentemente triviais e os lugares vazios do diálogo". Daí resulta o processo dinâmico da comunicação, dessa dialética de mostrar e de ocultar, pois é nessa relação que o dito ganha significância, quando ele remete ao que oculta.

Surge, então, o riso, sintoma de que as contradições arraigadas nos enunciados da entrevistada foram percebidas pelo leitor, impelido-o a assumir o que Bakhtin chama de "posição responsiva ativa", para determinar "uma série de inter-relações complexas, de consonâncias e multissonâncias com o compreendido" "56. Somente assim o leitor pode enxergar a realidade para além do nível fenomênico, atingindo, desse modo, o nível profundo das manifestações ideológicas.

Essa atitude reponsiva ativa se acentua em se tratando de uma narrativa cujo narrado é câmera, ou seja, uma focalização externa que apresenta apenas as ações das personagens, sem intermediação de vozes, acesso direto aos sentimentos e pensamentos delas. Assim sendo, cabe ao leitor a função de atar os fios, organizar as ideias do texto, o que coincide com a proposta do próprio livro Inescritos.

A história escrita remete a um espaço incircunscrito, pois o objeto não cobre a extensão da paisagem da obra. Sobre isso, afirma Blanchot, "a obra só está ali para levar [aquele que escreve] à busca da obra" ${ }^{, 57}$, como se estivesse diante da visão desse horizonte inatingível, que está sempre lá. Assim, diante do texto escrito, que carrega a ausência do que lhe escapa, do que nele não cabe, submerge um outro, que está "inescrito" e, portanto, aberto ao movimento interpretativo do leitor.

\section{Considerações finais}

Compreendendo a narrativa feminista como aquela que apresenta um "sujeito de enunciação consciente de seu papel social", uma consciência do eu da autora que se coloca na voz de personagens e narrador para mostrar "uma posição de confronto social" 58 , o conto analisado permite um olhar feminista, pois Luci Collin produz esse efeito crítico.

\footnotetext{
${ }^{56}$ CLARK, Katerina; HOLQUIST, Michael. Mikhail Bakhtin. São Paulo: Perspectiva, 1998, p. 63.

${ }^{57}$ BLANCHOT, Maurice. O livro por vir. Trad. Maria Regina Louro. Lisboa: Relógio d'Água, 1984, p. 210.

${ }^{58}$ LOBO, 1999 apud ZOLIN, 2003, p. 77.
} 
No entanto, ela o faz por meio de uma relação complexa de perspectivas. Ao criar uma personagem feminina que usufrui conquistas feministas nas esferas intelectual, cultural, social, econômica e, sobretudo, política, mas que não tem consciência de seu potencial emancipador e transformador na sociedade, a autora evidencia uma relação de emancipação apenas na materialidade linguística dos enunciados da protagonista, deixando, para o leitor, assim, a tarefa de estabelecer uma relação polêmica no nível profundo do discurso de Mara, a partir da leitura das forças antagônicas que pulsam dele.

Assim sendo, Collin eleva o leitor a uma posição decisiva no processo de interpretação, passando de leitor contemplativo, dirigido e passivo, a movente, crítico e dinâmico, condições imprescindíveis para apagar os vestígios da ideologia a que a protagonista acredita estar filiada e para revelar a sua identidade em sua complexidade.

A partir de uma leitura subsidiada em uma visão feminista, percebeu-se uma nova preocupação no concernente à mulher em um momento de pós-conquistas do feminismo, a qual diz respeito ao modo como essas elas são usufruídas pela mulher para transformar a sociedade. Embora o movimento feminista tenha promovido uma conquista fundamental na transformação das relações de gênero ao inserir as mulheres no espaço público, sobretudo, no político - lócus privilegiado para embates políticos e para a democratização da vida cotidiana, por se tratarem de espaços onde se constroem e legitimam discursos -, esse projeto amplo de transformação social é lento e complexo.

\section{Referências bibliográficas}

ÁVILA, Maria Betânia. Feminismo e sujeito político. Revista Proposta, Rio de Janeiro, n. 8485, p. 7-11, mar./ ago. 2000.

BEAUVOIR, Simone de. O segundo sexo II: a experiência vivida. 2.ed. Trad. de Sérgio Milliet. São Paulo: Difusão Européia do Livro, 1967.

BLANCHOT, Maurice. O livro por vir. Trad. Maria Regina Louro. Lisboa: Relógio d'Água, 1984.

BOURDIEU, Pierre. A dominação masculina. Trad. Maria Helena Kühner. 4.ed. Rio de Janeiro: Bertrand Brasil, 2005.

CLARK, Katerina; HOLQUIST, Michael. Mikhail Bakhtin. São Paulo: Perspectiva, 1998.

COLLIN, Luci. Inescritos. Curitiba: Travessa dos Editores, 2004. 
HALL, Stuart. Identidades culturais na pós-modernidade. Trad. Tomaz Tadeu Silva e Guacira Lopes Louro. Rio de janeiro: DP\&A, 1997.

ISER, Wolfgang. $O$ ato da leitura: uma teoria do efeito estético. vol. 1. Tradução Johannes Kretschmer. São Paulo: Ed. 34, 1996.

O ato da leitura: uma teoria do efeito estético. vol. 2. Tradução Johannes Kretschmer. São Paulo: Ed. 34, 1999.

LAURETIS, Teresa de. A tecnologia do gênero. In: HOLLANDA, Heloísa Buarque de. Tendências e impasses: o feminismo como crítica da cultura. Rio de Janeiro: Rocco, 1994.

OLIVEIRA, Nelson de. Inescritos, de Luci Collin. Jornal de Poesia. Disponível em: $<$ http://www.revista.agulha.nom.br/nelsonoliveira9.html $>$ Acesso em: 15 de ago. 2009.

ORLANDI, Eni Pulcinelli. Análise de Discurso: princípios e procedimentos. São Paulo: Pontes, 2001.

RAGO, Margareth. Adeus ao feminismo? Feminismo e (pós)modernidade no Brasil. Cadernos AEL - Arquivo Edgard Leuenroth: mulher, história e feminismo, Campinas, SP, n. 3/4, p. 11-43, 1995/1996.

ZOLIN, Lúcia Osana. O. Desconstruindo a opressão: a imagem feminina em A república dos sonhos de Nélida Piñon. Maringá: Eduem, 2003.

[Recebido em março de 2011 e aceito para publicação em maio de 2011]

DECONSTRUCTING EMANCIPATORIES SPEECHES: A FEMINIST ANALYSIS ON THE FEMALE CHARACTER IN POSITIONS OF POWER IN "ENTREVISTA AO VIVO", BY LUCI COLLIN

Abstract: This article aims to reflect on the achievements of feminism' influences over the female identities construction aware of its transforming potential. In order to do that, this work analyse the short story "Entrevista ao vivo" (Inescritos, 2003), by Luci Collin. As theoretical approach, the feminist criticism is applied to deal with issues like power relations between genders and literary representation.

Keywords: Female representation; Power relations; Feminist Criticism. 


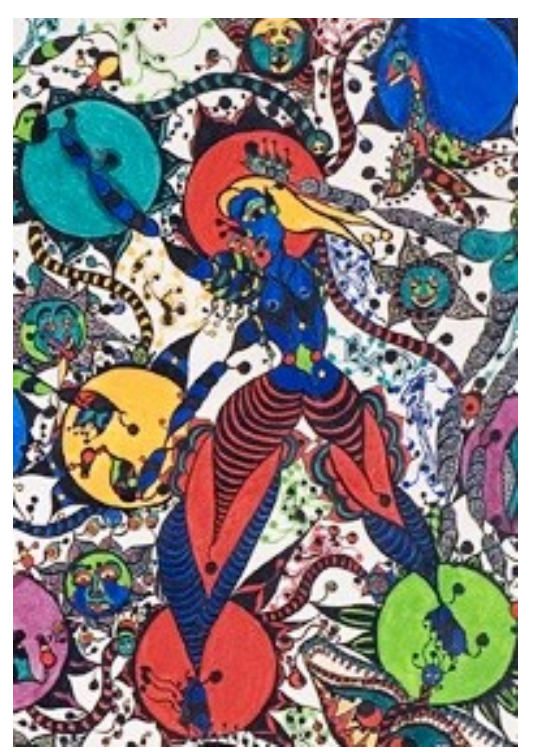

